\title{
FUNGICIDAS APLICADOS VIA ÁGUA DE IRRIGAÇÃO NO CONTROLE DO MOFO- BRANCO NO FEIJOEIRO E INCIDÊNCIA DO PATÓGENO NA SEMENTE
}

\author{
ROGÉRIO F. VIEIRA ${ }^{1}$, TRAZILBO J. DE PAULA JÚNIOR ${ }^{1}$, ÂNGELA P. PERES ${ }^{2} \&$ JOSÉ DA C. MACHADO ${ }^{2}$
}

\author{
'EPAMIG, Cx. Postal 216, CEP 36571-000, Viçosa, MG, e-mail:rfvieira@homenet.com.br; ${ }^{2}$ Departamento de \\ Fitopatologia, Universidade Federal de Lavras, Cx. Postal 37, CEP 37200-000, Lavras, MG
}

(Aceito para publicação em 14/08/2001)

Autor para correspondência: Rogério F. Vieira

VIEIRA, R.F., PAULA JÚNIOR, T.J. de, PERES, A.P. \& MACHADO, J. da C. Fungicidas aplicados via água de irrigação no controle do mofo-branco no feijoeiro e incidência do patógeno na semente. Fitopatologia Brasileira 26:770-773. 2001.

\section{RESUMO}

Foi instalado um experimento em Viçosa, MG, em 11 de abril, em área infestada por escleródios de Sclerotinia sclerotiorum, com o objetivo de testar a eficiência de quatro fungicidas aplicados via água de irrigação por aspersão no controle do mofo-branco do feijoeiro (Phaseolus vulgaris). Os seguintes fungicidas e doses do ingrediente ativo por hectare foram testados: benomyl $(1 \mathrm{~kg})$, iprodione $(0,75 \mathrm{~kg})$, procimidone $(0,5 \mathrm{~kg})$ e fluazinam $(0,51)$. As aplicações foram simuladas com regadores $(35.000$ 1/ha). A primeira aplicação foi feita aos 39 dias após a emergência (DAE); a segunda, 13 dias depois. Nesses mesmos dias, o fluazinam também foi aplicado com pulverizador (667 1/ha) ou com regador (35.000 1/ha) entre as fileiras de feijão e rente ao solo. Este último tratamento teve por objetivo verificar se o fluazinam aplicado apenas no solo tem efeito no controle da doença. Ademais, foi utilizada uma testemunha que não recebeu fungicida. Após a colheita, avaliou-se a incidência do fungo nas sementes. Os fungicidas fluazinam (aplicado com pulverizador ou via água de irrigação sobre as plantas), benomyl e procimidone foram os mais eficientes no controle do mofo-branco e, dentre eles, apenas o procimidone não proporcionou rendimento maior que o da testemunha. O fluazinam aplicado apenas no solo reduziu a incidência da doença e a quantidade de escleródios produzidos. Os rendimentos variaram de 1.406 (testemunha) a $2.054 \mathrm{~kg} /$ ha (fluazinam, pulverização). Não houve influência dos tratamentos na incidência do fungo nas sementes, a qual variou de $0,25 \%$ (procimidone) a $1,08 \%$ (fluazinam aplicado no solo).

Palavras-chave adicionais: Phaseolus vulgaris, Sclerotinia sclerotiorum, fungigação, transmissão por sementes.

\section{ABSTRACT \\ Fungigation on white mould control of common beans and seed transmission of the pathogen}

The effectiveness of four fungicides applied through irrigation water to control white mould of common beans (Phaseolus vulgaris) was evaluated in Viçosa, MG. The trial was installed on April in a naturally infested field with sclerotia of Sclerotinia sclerotiorum. The following fungicides and rates of active ingredient per hectare were tested: benomyl $(1.0 \mathrm{~kg})$, iprodione $(0.75 \mathrm{~kg})$, procymidone $(0.5 \mathrm{~kg})$, and fluazinam $(0.51)$. Simulating sprinkler irrigation, fungicides were applied with watering-cans over the plants at 39 and 52 days after emergence (DAE) with water volume of 35,000 1/ha. At these two periods, fluazinam was also applied by a backpack sprayer (667 l/ha) or with watering-cans $(35,000 \mathrm{l} / \mathrm{ha})$ between the rows and near the soil surface. The last treatment was to verify the fluazinam effect on white mould control when applied on the soil surface. An untreated plot was also included. After harvest, seed transmission of the pathogen was evaluated. Fluazinam (applied either by backpack sprayer or through irrigation water onto plants), benomyl, and procymidone were the most efficient fungicides for white mould control. Among them, only procymidone did not provide yield higher than that of control. Fluazinam applied only on soil reduced white mould incidence and the amount of sclerotia produced. Yields varied from $1,406 \mathrm{~kg} / \mathrm{ha}$ (control) to $2,054 \mathrm{~kg} / \mathrm{ha}$ (fluazinam applied by backpack sprayer). There was no effect of treatments on the pathogen seed transmission, which varied from $0.25 \%$ (procymidone) to $1.08 \%$ (fluazinam applied only on the soil).
Minas Gerais está entre os estados maiores produtores de feijão (Phaseolus vulgaris L.) do Brasil, com produção em torno de 300.000 t. O feijão plantado no outono ou no inverno e, portanto, colhido no inverno ou na primavera responde por $25 \%$ da produção (Santos \& Braga, 1998).
Nessas épocas de plantio, é necessário o uso de irrigação em Minas Gerais, por causa da escassez de chuvas durante o ciclo de vida dos feijoeiros. A condição de alta umidade proporcionada pela irrigação aliada às temperaturas amenas nesses plantios no meio do ano favorece o desenvolvimento 
Fungicidas aplicados via água de irrigação no controle do mofo-branco...

do mofo-branco, doença causada pelo fungo Sclerotinia sclerotiorum (Lib.) de Bary. O uso de sementes infetadas com micélio e/ou infestadas com escleródios são, provavelmente, as principais causas da introdução desse patógeno nas lavouras. Os escleródios podem germinar miceliogenicamente, infetando diretamente as plantas, ou, como é mais comum, carpogenicamente, produzindo apotécios que liberam ascosporos. Estes podem infetar a parte aérea das plantas. As flores dos feijoeiros servem como fonte básica de nutrientes nas infecções iniciadas por ascosporos. Por essa razão, o controle químico do mofo-branco depende da boa cobertura das flores com o fungicida. $\mathrm{O}$ uso de fungicidas apropriados tem ajudado no controle dessa doença. Em geral, é recomendada uma aplicação de fungicida no início da floração e, se as condições climáticas continuarem favoráveis à doença, uma segunda aplicação se faz necessária, 10-14 dias após a primeira. $\mathrm{O}$ uso de pulverizadores de barra tratorizados para a distribuição do fungicida é dificultado pelo fechamento do vão entre as fileiras de feijoeiro e pela necessidade de o fungicida ser aplicado em alto volume. A aplicação aérea, embora não cause danos mecânicos às plantas, não proporciona bons resultados, por causa do baixo volume de calda empregado (Tu, 1989). Uma alternativa utilizada por muitos agricultores é a aplicação do fungicida via água de irrigação por aspersão, técnica denominada fungigação. Embora haja poucos estudos sobre essa técnica no controle do mofo-branco, os resultados são alentadores (Vieira \& Sumner, 1999).

O objetivo deste trabalho foi testar a eficiência de quatro fungicidas aplicados via água de irrigação no controle do mofo-branco no feijoeiro, simulando a irrigação por aspersão com regadores. Também foi investigada a eficácia do fungicida fluazinam aplicado apenas sobre o solo.

Foi instalado um ensaio, em Viçosa, MG, em abril de 1997, em área da Universidade Federal de Viçosa uniformemente infestada por escleródios de $S$. sclerotiorum. Foi utilizada a variedade de feijoeiro preto Meia Noite (tipo II), plantado no espaçamento entre fileiras de $50 \mathrm{~cm}$, com cerca de 20 sementes por metro.

Cada parcela constou de quatro fileiras de $5 \mathrm{~m}$ de comprimento. No sulco de plantio foram distribuídos $700 \mathrm{~kg} /$ ha do formulado 4-14-8 $\left(\mathrm{N}-\mathrm{P}_{2} \mathrm{O}_{5}-\mathrm{K}_{2} \mathrm{O}\right)$. Em cobertura, aos 20 dias após a emergência (DAE), foram distribuídos, em filete ao lado das plantas, $95 \mathrm{~kg} / \mathrm{ha}$ de uréia. Nessa data, também foi feita pulverização das folhas com molibdato de sódio (equivalente a $80 \mathrm{~g} / \mathrm{ha}$ de Mo). A adubação em cobertura foi repetida 18 dias depois da primeira, com $200 \mathrm{~kg} / \mathrm{ha}$ de sulfato de amônio. Aos 27 DAE, foi feita pulverização das plantas com a mistura dos fungicidas tiofanato metílico $(400 \mathrm{~g} / \mathrm{ha}) \mathrm{e}$ chlorotalonil (1 kg/ha) para o controle da ferrugem [Uromyces appendiculatus (Pers.) Unger] e da mancha-angular [Phaeoisariopsis griseola (Sacc.) Ferraris]. O controle de insetos com deltametrina $(80 \mathrm{ml} / \mathrm{ha})$ foi feito sempre que a população de pragas, principalmente de cigarrinha-verde, era moderada. Foram feitas irrigações semanais com cerca de 50 $\mathrm{mm}$ de água. As plantas daninhas foram controladas com a mistura dos herbicidas de pós-emergência fomesafen ( $250 \mathrm{~g} /$ ha) e fluazifop-p-butil (200 g/ha).

Os seguintes fungicidas e doses do ingrediente ativo por hectare foram testados: benomyl $(1 \mathrm{~kg})$, iprodione $(0,75$ $\mathrm{kg})$, procimidone $(0,5 \mathrm{~kg})$ e fluazinam $(0,5 \mathrm{l})$. O benomyl, o iprodione e o procimidone foram usados na formulação pó molhável, e o fluazinam, como suspensão concentrada. Esses fungicidas foram aplicados com regadores, cada um com capacidade para 101 de água, sobre as plantas aos 39 e 52 DAE, simulando fungigação com volume de água de 35.000 1/ha (3,5 mm). Aos 39 DAE, 10\% dos feijoeiros apresentavam pelo menos uma flor aberta. Foram feitos ajustes no tamanho e no número de furos do regador de modo a padronizar o tempo de molhamento das plantas em quatro a cinco minutos. $O$ fungicida fluazinam também foi aplicado com regador ( $35.000 \mathrm{l} / \mathrm{ha}$ ) entre as fileiras dos feijoeiros e sobre a superfície do solo (sem molhar a parte aérea das plantas), e com pulverizador costal (667 1/ha). Como testemunha, foram utilizadas parcelas que não receberam fungicida para o controle do mofobranco. Portanto, foram testados sete tratamentos, dispostos no delineamento em blocos ao acaso, com seis repetições.

Foram feitas as seguintes avaliações: número de plantas murchas, incidência e severidade de mofo-branco, estande final, rendimento, peso e número de escleródios misturados com os grãos, peso de 100 grãos e incidência de S. sclerotiorum nas sementes. O número de plantas murchas causada por S. sclerotiorum foi determinado aos 73 DAE. A incidência de mofo-branco foi avaliada aos 82 e aos 95 DAE. A severidade do mofo-branco foi avaliada com base em escala de 1 a 9, adaptada de Hall \& Phillips (1996), em que: $1=$ todas as plantas sem sintoma da doença; 3 = maioria das plantas doentes com $1 \%$ a $25 \%$ dos caules e ramos infetados; $5=$ maioria das plantas doentes com $26 \%$ a $50 \%$ dos caules e ramos infetados; 7 = maioria das plantas doentes com 51\% a $75 \%$ dos caules e ramos infetados; $9=$ maioria das plantas doentes com $76 \%$ a $100 \%$ dos caules e ramos infetados. Essa avaliação foi realizada aos 95 DAE. Após a colheita, foram eliminadas as impurezas misturadas com os grãos utilizandose uma peneira que reteve os escleródios com mais de $2 \mathrm{~mm}$. Essas estruturas foram, então, separadas dos grãos, contadas e pesadas. Para avaliar a incidência de S. sclerotiorum nas sementes foi utilizada metodologia descrita por Peres (1996), utilizando-se 200 sementes de cada parcela. Foi anotada a percentagem de sementes infetadas.

O estande final médio por ocasião da colheita aos 107 DAE foi de 332 mil plantas por hectare, não havendo diferença significativa entre as médias dos tratamentos. A testemunha apresentou o maior número de plantas murchas (Tabela 1), mas não diferiu significativamente dos tratamentos fluazinam, via água de irrigação; fluazinam, aplicado sobre o solo; e iprodione. A maior incidência de plantas com mofo-branco, tanto aos 82 DAE como aos 95 DAE, deu-se na testemunha sem fungicida (Tabela 1). A aplicação do fluazinam apenas sobre o solo também mostrou-se eficiente na redução da incidência de plantas doentes, talvez por inibir a formação de apotécios. Trabalhando com o fungicida vinclozolin, Costa 
TABELA 1 - Incidência e severidade de mofo-branco, rendimento do feijoeiro (Phaseolus vulgaris), peso e número de escleródios misturados com os grãos e peso de 100 grãos verificados nos diferentes tratamentos com fungicidas, em Viçosa, MG, em 1997'

\begin{tabular}{|c|c|c|c|c|c|c|c|c|}
\hline \multirow[b]{2}{*}{ Tratamento } & \multicolumn{4}{|c|}{ Mofo-branco $^{1}$} & \multirow{2}{*}{$\begin{array}{c}\text { Rendimento } \\
(\mathrm{kg} / \mathrm{ha})\end{array}$} & \multicolumn{2}{|c|}{$\begin{array}{c}\text { Escleródios misturados } \\
\text { com grãos }{ }^{* 2}\end{array}$} & \multirow{2}{*}{$\begin{array}{c}\text { Peso de } \\
100 \text { grãos } \\
\quad \text { (g) }\end{array}$} \\
\hline & $\begin{array}{c}\text { Plantas } \\
\text { murchas } \\
(73 \text { DAE) }\end{array}$ & $\begin{array}{c}\text { Incidência }^{3} \\
\text { (82 DAE) }\end{array}$ & $\begin{array}{c}\text { Incidência }^{3} \\
\text { (95 DAE) }\end{array}$ & $\begin{array}{c}\text { Severidade }^{4} \\
\text { (95 DAE) }\end{array}$ & & Peso (g) & Número & \\
\hline Fluazinam (pulverização) & $0,50 \mathrm{~b}$ & $19,7 \mathrm{~b}$ & $18,0 \mathrm{~b}$ & $4,83 \mathrm{~b}$ & $2.054 \mathrm{a}$ & $2,42 \mathrm{~b}$ & $276,0 \mathrm{~b}$ & $16,9 \mathrm{ab}$ \\
\hline Fluazinam (regador) & $1,50 \mathrm{ab}$ & $20,3 \mathrm{~b}$ & $22,2 \mathrm{~b}$ & $4,92 \mathrm{~b}$ & $1.827 \mathrm{ab}$ & $3,68 \mathrm{~b}$ & $431,7 \mathrm{~b}$ & $17,1 \mathrm{ab}$ \\
\hline Benomyl (regador) & $1,17 \mathrm{~b}$ & $19,0 \mathrm{~b}$ & $16,2 \mathrm{~b}$ & $4,83 \mathrm{~b}$ & $1.785 \mathrm{ab}$ & $2,52 \mathrm{~b}$ & $267,0 \mathrm{~b}$ & $17,9 \mathrm{a}$ \\
\hline Procimidone (regador) & $0,17 \mathrm{~b}$ & $12,9 \mathrm{~b}$ & $18,0 \mathrm{~b}$ & $4,58 \mathrm{~b}$ & $1.681 \mathrm{bc}$ & $2,05 \mathrm{~b}$ & $219,8 \mathrm{~b}$ & $16,7 \mathrm{ab}$ \\
\hline Iprodione (regador) & $2,50 \mathrm{ab}$ & $15,4 \mathrm{~b}$ & $18,2 \mathrm{~b}$ & $5,17 \mathrm{ab}$ & $1.618 \mathrm{bc}$ & $3,40 \mathrm{~b}$ & $383,2 \mathrm{~b}$ & $16,8 \mathrm{ab}$ \\
\hline Fluazinam (regador, sobre o solo) & $2,83 \mathrm{ab}$ & $11,5 \mathrm{~b}$ & $22,2 \mathrm{~b}$ & $5,17 \mathrm{ab}$ & $1.535 \mathrm{bc}$ & $3,64 \mathrm{~b}$ & $391,5 b$ & $17,2 \mathrm{ab}$ \\
\hline Testemunha sem fungicida & $4,83 \mathrm{a}$ & $35,4 \mathrm{a}$ & $46,0 \mathrm{a}$ & $6,08 \mathrm{a}$ & $1.406 \mathrm{c}$ & $6,98 \mathrm{a}$ & $844,8 \mathrm{a}$ & $15,5 \mathrm{~b}$ \\
\hline Média & 1,93 & 19,17 & 22,95 & 5,08 & $1.700,9$ & 3,52 & 402,0 & 16,86 \\
\hline C.V. $(\%)$ & 96,6 & 37,4 & 35,0 & 10,8 & 10,9 & 35,9 & 36,9 & 5,6 \\
\hline
\end{tabular}

${ }^{1} \mathrm{Na}$ coluna, as médias seguidas da mesma letra não diferem significativamente entre si pelo teste de Tukey, a $5 \%$.

${ }^{2}$ Escleródios com tamanho superior a $2 \mathrm{~mm}$ misturados com as sementes colhidas em $4 \mathrm{~m}^{2}$.

${ }^{3}$ Número de plantas infetadas em $4 \mathrm{~m}^{2}$.

${ }^{4}$ Severidade: 1 - plantas sem sintoma da doença, 3 - maioria das plantas doentes com $1 \%$ a $25 \%$ dos caules e ramos infetados, 5 - maioria das plantas doentes com $26 \%$ a $50 \%$ dos caules e ramos infetados, 7 - maioria das plantas doentes com $51 \%$ a $75 \%$ dos caules e ramos infetados, 9 - maioria das plantas doentes com $76 \%$ a 100\% dos caules e ramos infetados (adaptado de Hall \& Phillips, 1996).

\& Costa (1998) verificaram que a aplicação dele em volume de água simulando uma lâmina de $8 \mathrm{~mm}$ inibiu em $100 \%$ a formação de apotécios. Os escleródios haviam sido enterrados a $2 \mathrm{~cm}$ de profundidade. A maior média de severidade do mofo-branco também ocorreu na testemunha, mas esta não diferiu significativamente dos tratamentos de iprodione e de fluazinam (regador, sobre o solo) (Tabela 1).

A maior média de rendimento foi alcançada com o fluazinam aplicado com pulverizador costal $(2.054 \mathrm{~kg} / \mathrm{ha})$, mas ela não diferiu significativamente da do fluazinam e da do benomyl, ambos aplicados via água de irrigação. Esses resultados demonstram que a aplicação do fluazinam e do benomyl via água de irrigação foi eficiente no controle do mofo-branco. Em trabalho conduzido por dois anos em Guaíra, SP, Oliveira et al. (1995) verificaram que a fungigação ( $31.000 \mathrm{l} / \mathrm{ha}$ ) foi tão ou mais eficiente no controle do mofobranco que a aplicação de fungicidas com pulverizador (300 1/ha).

O número e o peso de escleródios misturados com os grãos (Tabela 1) foi maior na testemunha $\left(6,98 \mathrm{~g} / 4 \mathrm{~m}^{2}\right.$ ou 17,4 $\mathrm{kg} / \mathrm{ha}$ de escleródios). Não houve diferença significativa entre os tratamentos com fungicida no que diz respeito ao peso de 100 grãos, mas os grãos produzidos por plantas que receberam o benomyl aplicado via água de irrigação foram mais pesados que os produzidos por plantas que não receberam fungicida (Tabela 1).

A incidência de $S$. sclerotiorum nas sementes foi a seguinte: $1,08 \%$ (fluazinam aplicado apenas sobre o solo), $0,75 \%$ (fluazinam, pulverização), $0,66 \%$ (benomyl), $0,41 \%$ (fluazinam, via água de irrigação, iprodione e testemunha) e $0,25 \%$ (procimidone). Não houve diferença significativa entre os tratamentos. Utilizando dois métodos (“deep-freezing" e plaqueamento em agar) para a detecção de $S$. sclerotiorum nas sementes de feijão, Oliveira et al. (1995) verificaram que a incidência variou de $0,5 \%$ a $0,9 \%$, e que os métodos de aplicação (convencional e fungigação) não tiveram influência sobre a incidência do patógeno nas sementes.

Os resultados obtidos neste estudo também foram alcançados em outros estudos de fungigação para o controle do mofo-branco conduzidos no Brasil e nos EUA (Vieira \& Sumner, 1999). Nesta revisão, os autores demonstraram que essa técnica é eficiente para o controle de muitas outras doenças, mesmo com volume de água superior a $50.000 \mathrm{l} / \mathrm{ha}$. Segundo esses autores, a redução do resíduo de fungicida no alvo, causada pelo grande volume de água usada na fungigação, em relação aos métodos convencionais, pode ser compensada, pelo menos em parte, pelos seguintes fatores: a) melhor distribuição do fungicida no dossel das plantas, b) maior redução do inóculo na planta e no solo, c) absorção dos fungicidas sistêmicos pelas raízes, e d) melhor uniformidade de distribuição do produto pelo pivô-central. Além de reduzir muito o custo de aplicação do fungicida, essa técnica tem as seguintes vantagens: não causa compactação do solo e danos mecânicos às plantas, e, dependendo do fungicida, proporciona melhor controle de patógenos de solo que os métodos convencionais (Vieira \& Sumner, 1999).

\section{REFERÊNCIAS BIBLIOGRÁFICAS}

COSTA, G.R. \& COSTA, J.L. da S. Efeito do fungicida vinclozolin na formação de apotécios de Sclerotinia sclerotiorum no solo. Fitopatologia Brasileira 23:235. 1998 (Resumo).

HALL, R. \& PHILLIPS, L.G. Evaluation of parameters to 
assess resistance of white bean to white mold. Annual Report of the Bean Improvement Cooperative 39:306307. 1996.

OLIVEIRA, S.H.F., RECCO, C.A., SUGAHARA, E. \& OLIVEIRA, D.A. Avaliação comparativa da fungigação e aplicação convencional de fungicidas para controle de Sclerotinia sclerotiorum em feijoeiro. Summa Phytopathologica 21:249-252. 1995.

PERES, A.P. Detecção de Sclerotinia sclerotiorum (Lib.) de Bary em sementes de feijão (Phaseolus vulgaris L.) e soja (Glycine max L. Merril): desenvolvimento de metodologia. (Tese de Mestrado). Lavras. Universidade Federal de Lavras. 1996.

SANTOS, M.L. dos \& BRAGA, M.J. Aspectos econômicos. In: Vieira, C., Paula Jr., T.J. de \& Borém, A. (Eds.). Feijão: aspectos gerais e cultura no Estado de Minas. Viçosa. Editora UFV. 1998. pp. 19-53.

TU, J.C. Management of white mold of white beans in Ontário. Plant Disease 73:281-285. 1989.

VIEIRA, R.F. \& SUMNER, D.R. Application of fungicides to foliage through overhead sprinkler irrigation - a review. Pesticide Science 55:412-422. 1999. 